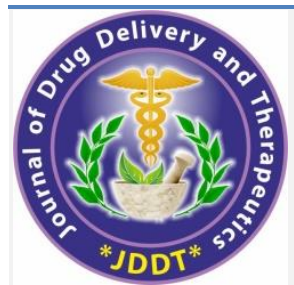

Access Full Text Article
Available online on 15.11.2021 at http://jddtonline.info

\section{Journal of Drug Delivery and Therapeutics}

Open Access to Pharmaceutical and Medical Research

Copyright (C) 2021 The Author(s): This is an open-access article distributed under the terms of the CC BY-NC 4.0 which permits unrestricted use, distribution, and reproduction in any medium for non-commercial use provided the original author and source are credited

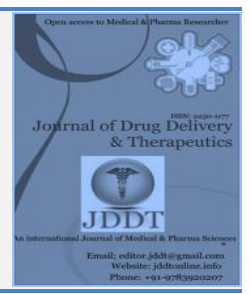

Research Article

\title{
Association of Body Mass Index with Serum Vitamin D and PSA Levels among Sudanese Prostate Cancer Patients
}

\author{
Yousif Abdelhameed Mohammed ${ }^{1}$, Ameer M Dafalla², Dafalla 0 Abuidris ${ }^{3}$, Adam D. Abakar ${ }^{4}$, A Mergani ${ }^{2}$, \\ Amira S. Khalafalla5, Abuagla M. Dafalla ${ }^{5}$, Mutaz I. Hassan 6, Mohammed Abdelwahed ${ }^{2}$ \\ ${ }^{1}$ Medial Laboratory Department, National Cancer Institute, University of Gezira, Wad Medani, Sudan \\ ${ }^{2}$ Molecular Biology Department National Cancer Institute, University of Gezira, Wad Medani, Sudan \\ ${ }^{3}$ Oncology Department, National Cancer Institute, University of Gezira, Wad Medani, Sudan \\ ${ }^{4}$ Department of Medical Parasitology, Faculty of Medical Laboratory Science, University of Gezira, Wad Medani, Sudan \\ ${ }^{5}$ Department of Clinical Chemistry, Faculty of Medical Laboratory Science, University of Gezira, Wad Medani, Sudan \\ ${ }^{6}$ Department of Clinical Chemistry, Faculty of Medical Laboratory Sciences, Shendi University, Sudan
}

Article Info:

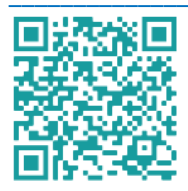

\section{Article History:}

Received 07 September 2021 Reviewed 12 October 2021 Accepted 18 October 2021 Published 15 November 2021

\section{Cite this article as:}

Mohammed YA, Dafalla AM, Abuidris DO, Abakar AD, Mergani A, Khalafalla AS, Dafalla AM, Hassan MI, Abdelwahed M, Association of Body Mass Index with Serum Vitamin D and PSA Levels among Sudanese Prostate Cancer Patients, Journal of Drug Delivery and Therapeutics. 2021; 11(6):1-5

DOI: http://dx.doi.org/10.22270/jddt.v11i6.5029

\section{*Address for Correspondence:}

Dr. Mutaz I. Hassan, Department of Clinical Chemistry, Faculty of Medical Laboratory Sciences, Shendi University, Sudan

\section{Abstract}

Background: Prostate cancer is the second most common cancer in men worldwide and the second leading cause of cancer deaths in men in the United States. Obesity has been consistently associated with lower 25-hydroxyvitamin D (25(OH)D) concentrations.

Objectives: This cross-sectional study aimed to evaluate the serum vitamin D and PSA levels in Sudanese Obese and Non-Obese prostate cancer (PCa) attending the National Cancer Institute.

Patients and Methods: Eighty six prostate cancer patients were included in this study, they were identified by clinical examination, histopathology and prostate-specific antigen (PSA). The mean age of them was $71.78 \pm 8.04$ years. Serum Vitamin D and PSA were measured by Electrochemiluminescence (ECL) immunoassay reactions using (Cobase411, serial No: 086816, manufactured by Hitachi high technologies corporation, Tokyo-Japan) the Elecsys reagents kit (Roche - Germany)

Results: The means of serum vitamin D levels of among obese was $35.5 \pm 15.4 \mathrm{ng} / \mathrm{dL}$ and $38.4 \pm 16.2 \mathrm{ng} / \mathrm{dL}$ among non-obese group with non-significant differences(P=0.505). No significant association was observed between PSA levels and obese and non-obese $(\mathrm{P}=0.351)$. Vitamin D levels non-significantly negative correlated with BMI $(r=-0.031, P=0.778)$ and PSA ( $r=-0.062, P=0.569)$, but there was insignificantly Positive correlated between PSA and vitamin D level $(\mathrm{r}=0.151, \mathrm{P}=0.164)$.

Conclusion: insignificant differences between vitamin D and serum PSA with BMI, Oral supplementation is recommended for individuals with low level of vitamin D.

\section{INTRODUCTION}

Prostate cancer (PCa) is one of the most common type of cancer among men in the Unite State of America, and African American (AA) men have higher prevalence and mortality rates compared to European American (EA) men and different racial/ethnic corporations 1 . Sudan changed into the largest country in Africa until 2011, when South Sudan separated into an impartial country. The prevalence of prostate cancer within the Sudan becomes the most common type among the Sudanese men based on GLOBOCAN 2018 estimating prostate cancer to $9.2 \%$ among adult males, all ages ${ }^{2}$.
Obesity is a problem that deserves international attention. Many researches have proven that obesity can result in many physical and mental diseases along with diabetes, cardiovascular disease, cancer, and despair 3, 4. Obesity is also related to insulin, blood pressure, glucose and metabolic syndrome 5. The prevalence of weight problems is developing hastily ${ }^{6}$. Body Mass Index (BMI) and serum lipid parameters expect growing chance of competitive prostate cancer in human beings in China ${ }^{7}$.

Prostate-specific antigen (PSA) is a hallmark of prognosis of prostate cancer $\mathbf{8}$. Regardless of age unique consequences, the threshold of PSA is often used as an indicator of pathological diagnosis of prostate most cancers. However 
one take a look at has determined that BMI could influence PSA tiers ${ }^{9}$. seo et al. were given the same end: with the BMI increasing, the PSA tiers reduced $\mathbf{1 0}$.

\section{PATIENTS AND METHODS:}

\section{Setting and Patients:}

This is a cross-sectional based-hospital study that was conducted at the National Cancer Institute (NCI), Gezira University, Wad Medani, and Sudan. Sudanese males with PCa attending the National Cancer Institute from 2020 to 2021.

\section{Study Population}

Known prostate cancer clinically and histopathological proven to have prostatic cancers. Through transurethral resection of the prostate (TURP) or Transurethral electro vaporization of the prostate(TVP) or Transrectal Ultrasound guided prostate biopsy (TRUS) and had PSA more than 4.00 $\mathrm{ng} / \mathrm{mL}$.

\section{Anthropometric Measurements}

Weight, height and body mass index were measured. All patients' height and weight were taken. Body mass index was obtained using formula

$$
\text { BMI }=\frac{(\text { Weight })(\text { Kg })}{(\text { Height })^{2}(\mathrm{~m})^{2}}
$$

\section{Inclusion Criteria}

All patients during study period newly confirmed diagnosed with PCa following histopathological examination or they were at advanced stage of the disease and were under radiation therapy will be enrolled in this study.

\section{Exclusion Criteria}

Patients with PCa excluded from this study if they are severely illness, renal diseases, malabsorption, hyperparathyroidism, any other cancer, and users of calcium lowering therapy, and those who taking vitamin D supplements.

\section{Sampling and Vitamin D Measurement: \\ Collection of blood:}

$2.5 \mathrm{ml}$ venous blood sample was obtained from each patients using standard venipuncture technique. Plasma specimens were collected as heparinized container after centrifugation at $3000 \mathrm{rpm}$ for 5 minutes. Then plasma was Pipette into a clean plastic screw-cap vial and attaches the label.

\section{Vitamin D and PSA Assay}

Vitamin D and PSA was measured by Electrochemiluminescence (ECL) immunoassay reactions using (Cobase411, serial No: 0868-16, manufactured by Hitachi high technologies corporation, Tokyo-Japan) the Elecsys reagents kit (Roche - Germany) was used, Elecsys reagent kits. Specify the cut-off values were:

- $<20 \mathrm{ng} / \mathrm{ml}$ is considered to be vitamin D deficiency.

- $21-29 \mathrm{ng} / \mathrm{ml}$ is considered to be insufficient.

- $>30 \mathrm{ng} / \mathrm{ml}$ is considered to be normal.

- $>100 \mathrm{ng} / \mathrm{ml}$ is considered to be toxic.

\section{Data analysis:}

Data was analyzed by SPSS software version (22) Patient clinico-demographic and anthropometric characteristics were presented as frequencies ( $\mathrm{n}$ and \%), mean \pm standard deviation (SD) and range of values. The ANOVAtest was used to assess the differences of vitamin $\mathrm{D}$ between groups. A pvalue $\leq 0.05$ was considered as statistically significant.

Ethical approval: Each participant was informed about the goal of the study and signed an informed consent before participation. The ethical committee at the Gezira State Health Ministry and the National Cancer Institute, University of Gezira, approved this study

\section{RESULTS}

\section{Socio-demographic characteristics of study population:}

Overall, 86 PCa patients attending National Cancer Institute were enrolled. PCa patients were in the age group of $<70$ years representing $51 \%$, and $49 \%$ in age group $>70$ years. The mean and median age was $71.78 \pm 8.04$ and 70 years, respectively. Only $12 \%$ of them were currently unmarried being divorced, widowed or separated while the remaining $88 \%$ were married. $68 \%$ of the participants were from Gezira state followed by Sinner $14 \%$. Education-wise, $76 \%$ of PCa patients had secondary school level while $20 \%$ and $4 \%$ were reported to have higher school and university levels, respectively. $37 \%$ had $\mathrm{BMI}$, and the remaining $36 \%$, and $12 \%$ men were daily workers and other type jobs. Majority of PCa patients were at Gleason Stage of 7 to 10 which accounted for $79 \%$, while the remaining $14 \%, 5 \%$ and $2 \%$ were at 6,4 and 3 Gleason Stage, respectively, majority of the patients $(86 \%)$ hasn't family history with cancer.(57\%) of patients involve bone metastasis,vitamin D deficiency constitute about (12.8\%) while Insufficient(19.8\% ) (Table 1). 
Table 1: Socio-demographic and clinical characteristics of the study Sudanese population with prostate cancer.Data shown are frequencies ( $\mathrm{n}$ and \%).

\begin{tabular}{|c|c|c|c|}
\hline \multicolumn{2}{|l|}{ Characteristics } & $\mathrm{n}$ & $\%$ \\
\hline \multirow[t]{3}{*}{ Age, Years } & $<70$ & 44 & 51 \\
\hline & $>70$ & 42 & 49 \\
\hline & Total & 86 & 100 \\
\hline \multirow[t]{9}{*}{ State of Residence } & Alqadarif & 6 & 7 \\
\hline & Blue Nile & 2 & 2 \\
\hline & Gezira & 56 & 68 \\
\hline & Kordofan & 2 & 2 \\
\hline & River Nile & 2 & 2 \\
\hline & Sinner & 12 & 14 \\
\hline & West Kurdufan & 1 & 1 \\
\hline & White Nile & 3 & 4 \\
\hline & Total & 86 & 100 \\
\hline \multirow[t]{5}{*}{ Marital Status } & Divorced & 1 & 1 \\
\hline & Married & 76 & 88 \\
\hline & Single & 2 & 3 \\
\hline & Widower & 7 & 8 \\
\hline & Total & 86 & 100 \\
\hline \multirow[t]{7}{*}{ Education Level } & Higher school & 17 & 19.8 \\
\hline & Illiterate & 23 & 26.7 \\
\hline & Preprimary & 15 & 17.4 \\
\hline & Primary & 26 & 30.2 \\
\hline & Secondary school & 1 & 1.2 \\
\hline & University & 4 & 4.7 \\
\hline & Total & 86 & 100 \\
\hline \multirow[t]{8}{*}{ Gleason Stage } & 3 & 2 & 2.3 \\
\hline & 4 & 4 & 4.7 \\
\hline & 6 & 12 & 14 \\
\hline & 7 & 18 & 20.9 \\
\hline & 8 & 20 & 23.3 \\
\hline & 9 & 22 & 25.6 \\
\hline & 10 & 8 & 9.3 \\
\hline & Total & 86 & 100 \\
\hline \multirow[t]{6}{*}{ Gleason Grade } & I & 18 & 20.9 \\
\hline & II & 7 & 8.1 \\
\hline & III & 9 & 10.5 \\
\hline & IV & 22 & 25.6 \\
\hline & $\mathrm{V}$ & 30 & 34.9 \\
\hline & Total & 86 & 100 \\
\hline \multirow[t]{5}{*}{ Body Mass Index } & Underweight & 7 & 8.1 \\
\hline & Normal weight & 33 & 38.4 \\
\hline & Overweight & 30 & 34.9 \\
\hline & Obese & 16 & 18.6 \\
\hline & Total & 86 & 100 \\
\hline \multirow[t]{3}{*}{ Family History of cancer } & No & 74 & 86 \\
\hline & Yes & 12 & 14 \\
\hline & Total & 86 & 100 \\
\hline \multirow[t]{3}{*}{ Bone metastasis } & No & 37 & 43 \\
\hline & Yes & 49 & 57 \\
\hline & Total & 86 & 100 \\
\hline \multirow[t]{4}{*}{ Vitamin D Level } & vitamin D deficiency & 11 & 12.8 \\
\hline & Insufficient & 17 & 19.8 \\
\hline & Normal & 58 & 67.4 \\
\hline & Total & 86 & 100 \\
\hline
\end{tabular}


They was mild deceased in vitamin D level in obese with when compared with non-obese $(35.5 \pm 15.4$ and $38.4 \pm 16.2)$ without significant differences $(P=0.505)$ also there was decrease of serum PSA among obese when compared with non-obese (241.6 via 422.1) without significant differences $(\mathrm{P}=0.351)$ (table 2).

Table 2

\begin{tabular}{|l|l|l|l|l|l|}
\hline & Obese and non-obese & $\mathbf{N}$ & Mean & Std. Deviation & P-Value \\
\hline PSA & Obese & 16 & 214.6 & 222.4 & \multirow{2}{*}{$0.351^{*}$} \\
\hline & Non Obese & 70 & 422.1 & 915.7 & \multirow{2}{*}{0.505} \\
\cline { 1 - 3 } & Obese & 16 & 35.5 & 15.4 & \\
\end{tabular}

*The Mann-Whitney test

They were weakly insignificant negative correlation between BMI and vitamin D and PSA ( $\mathrm{r}=-0.031, \mathrm{P}=0.778)$ and $(\mathrm{r}=$ $0.062, \mathrm{P}=0.569$ ) respectively, also there were insignificantly

Positive correlated between PSA and vitamin D level $(\mathrm{r}=$ $0.151, \mathrm{P}=0.164$ ) (table3).

Table 3

\begin{tabular}{|l|l|l|l|l|}
\hline & & PSA & Vitamin D Level & BMI \\
\hline \multirow{4}{*}{ PSA } & Pearson Correlation & 1 & 0.151 & -0.062 \\
\cline { 2 - 5 } & Sig. (2-tailed) & 86 & 0.164 & 0.569 \\
\cline { 2 - 5 } & $\mathrm{N}$ & 0.151 & 1 & 86 \\
\hline \multirow{5}{*}{ Vitamin D Level } & Pearson Correlation & 0.164 & & -0.031 \\
\cline { 2 - 6 } & Sig. (2-tailed) & 86 & 86 & 0.778 \\
\cline { 2 - 6 } & $\mathrm{N}$ & -0.062 & -0.031 & 86 \\
\hline \multirow{5}{*}{ BMI } & Pearson Correlation & 0.569 & 0.778 & 1 \\
\cline { 2 - 5 } & Sig. (2-tailed) & 86 & 86 & 86 \\
\cline { 2 - 5 } & $\mathrm{N}$ & & & \\
\hline
\end{tabular}

\section{DISCUSSION:}

Sociodemographic analysis of participants showed that majority of patients were from Gezira state and, others were coming from all over the Sudan. This may be explained by the fact that this study conducted at National Cancer. Age distribution of participants in the current study showed predominance of advance age among PCa patients with a mean age which was lower than studies done in Sudan11,12, but higher than another Sudanese study ${ }^{13}$ and then another report from Uganda11. This variation in result may be due to variation in sample size among studies, also the increased of age among PCa patient may due to absent of screening program for prostate cancer in Sudan. Majority of patients were present with advanced local stage of disease. This is similar to different studies conducted in Sudan 11,12,14. This finding may be due to lack of awareness among Sudanese and absence of screening program for prostate cancer in Sudan.

There were insignificant differences between vitamin $D$ level and obesity this finding agree with Nair-Shalliker $V$ et al $\mathbf{1 9}$. Also there were insignificant negative correlation between $\mathrm{BMI}$ and vitamin D level, this finding is consistent with the results of several publications demonstrating a negative correlation between that the vitamin D levels and BMI 15, 16 . Moreover, Seo et al. also found that age was negatively correlated with BMI 10.
Seo et al reported that higher BMI was associated with lower PSA levels. But the correlation was much weak, this finding in line with our finding in week correlation but it contrary to

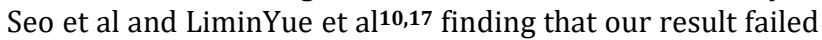
to find significant correlation .A study from Jeong et al. illustrated that PSA level was confirmed to increase with decreasing BMI, which was in correspondence with our research 18

\section{CONCLUSION:}

There were negative correlation between BMI and Serum vitamin D and PSA level among patients with prostate Cancer.

\section{REFERENCES}

1- Siegel RL, Miller KD, Jemal A. Cancer statistics, 2015. CA Cancer J Clin. 2015; 65(1):5-29. https://doi.org/10.3322/caac.21254

2- Rashid M, Shamshavali K, Chhabra M. Efficacy and Safety of Nilutamide in Patients with Metastatic Prostate Cancer who Underwent Orchiectomy: A Systematic Review and

Metaanalysis. CurrClinPharmacol. 2019; 14(2):108-115. https://doi.org/10.2174/1574884714666190112151202

3- Guh DP, Zhang W, Bansback N, Amarsi Z, Birmingham CL, Anis $\mathrm{AH}$. The incidence of co-morbidities related to obesity and overweight: a systematic review and meta-analysis. BMC Public Health. 2009; 9:88. Published 2009 Mar 25. https://doi.org/10.1186/1471-2458-9-88 
4- Faith MS, Butryn M, Wadden TA, Fabricatore A, Nguyen AM, Heymsfield SB. Evidence for prospective associations among depression and obesity in population-based studies. Obes Rev. 2011; 12(5):e438-e453. https://doi.org/10.1111/j.1467789X.2010.00843.x

5- Truesdale KP, Stevens J, Lewis CE, Schreiner PJ, Loria CM, Cai J. Changes in risk factors for cardiovascular disease by baseline weight status in young adults who maintain or gain weight over 15 years: the CARDIA study. Int J Obes (Lond). 2006; 30(9):1397-1407. https://doi.org/10.1038/sj.ijo.0803307

6- Parikh NI, Pencina MJ, Wang TJ, et al. Increasing trends in incidence of overweight and obesity over 5 decades. Am J Med. 2007; 120(3):242-250. https://doi.org/10.1016/j.amjmed.2006.06.004

7- Zhao R, Cheng G, Wang B, et al. BMI and serum lipid parameters predict increasing risk and aggressive prostate cancer in Chinese people. Oncotarget. 2017; 8(39):66051-66060. Published 2017 Aug 2. https://doi.org/10.18632/oncotarget.19790

8- Albertsen PC. Prostate cancer screening and treatment: where have we come from and where are we going?. BJU Int. 2020; 126(2):218-224. https://doi.org/10.1111/bju.15153

9- Freedland SJ, Wen J, Wuerstle M, et al. Obesity is a significant risk factor for prostate cancer at the time of biopsy. Urology. 2008; 72(5):1102-1105. https://doi.org/10.1016/j.urology.2008.05.044

10- Seo DH, Yoon S, Choi JH, et al. The Correlation between Body Mass Index and Routine Parameters in Men Over Fifty. World J Mens Health. 2017; 35(3):178-185. https://doi.org/10.5534/wjmh.16032

11- TAHA, S. M., WENG, H.-Y., MOHAMMED, M. E. I., OSMAN, Y. M., N'DRI, N. S., MOHAMMED, S. I. \& ABUIDRIS, D. O. 2020. Prostate cancer clinical characteristics and outcomes in Central Sudan. ecancermedicalscience, 14 . https://doi.org/10.3332/ecancer.2020.1116

12- Elgasim, M. A. E. A., Suleiman, Y., Ahmed ELmubark, E. M. E., Abdalmahmoud, A. A. A., Babkeir, S. A. M., Omer, R., Yasin, R.,
Abaker, K. E. A., Babker, R. O. A., Alryah, A., \&Alzain, T. Benefits of Docetaxel for Metastatic Castration-Resistant Prostate Cancer Sudanese Patients and the Effective Number of Cycle and Dose (2013-2017). International Research Journal of Oncology, 2019; 2(2):1-9. Retrieved from https://journalirjo.com/index.php/IRJO/article/view/30100.

13- Abu El Maaty MA, Alborzinia H, Khan SJ, Büttner M, Wölfl S. 1,25(OH)2D3 disrupts glucose metabolism in prostate cancer cells leading to a truncation of the TCA cycle and inhibition of TXNIP expression. BiochimBiophysActaMol Cell Res. 2017 Oct; 1864(10):1618-1630.

https://doi.org/10.1016/j.bbamcr.2017.06.019

14- Gorish BM, Ournasseir ME, Shammat IM. Effect of Age, Geographical Affiliation and Environmental Factors on the Development of Prostate Cancer among Sudanese Patients. J Carcinog Mutagen. 2019; 10(3):pp(337).

15- Jungert A, Neuhäuser-Berthold M. Cross-sectional and longitudinal associations between serum 25 hydroxyvitamin $D$ and anti-oxidative status in older adults. ExpGerontol. $2018 \mathrm{Sep}$ 110:291-297. https://doi.org/10.1016/j.exger.2018.06.024

16- Datta M, Schwartz GG. Calcium and vitamin D supplementation during androgen deprivation therapy for prostate cancer: a critical review. Oncologist. 2012; 17(9):1171-9. https://doi.org/10.1634/theoncologist.2012-0051

17- Yue L, Ge Y, Wang T, Ge M, Zhang C, Zhang W. The correlation between body mass index and prostatic-related parameters in men 40 years or older in Zhengzhou. Aging Male. 2020; 23(5):483- https://doi.org/10.1080/13685538.2018.1530754

18- Jeong IG, Hwang SS, Kim HK, Ahn H, Kim CS. The association of metabolic syndrome and its components with serum prostatespecific antigen levels in a Korean-screened population. Cancer Epidemiol Biomarkers Prev. 2010; 19(2):371-380. https://doi.org/10.1158/1055-9965.EPI-09-0760

19- Nair-Shalliker V, Bang A, Egger S, et al. Post-treatment levels of plasma 25- and 1,25-dihydroxy vitamin $\mathrm{D}$ and mortality in men with aggressive prostate cancer. Sci Rep. 2020; 10(1):7736. Published 2020 May 8. https://doi.org/10.1038/s41598-02062182-w 